\title{
Design of high power amplifier based on wilkinson power combiner for wireless communications
}

\author{
Tran Van Hoi ${ }^{1}$, Ngo Thi Lanh ${ }^{2}$ \\ ${ }^{1}$ Faculty of Electrical and Electronic Engineering, Thuyloi University, Viet Nam \\ ${ }^{2}$ Faculty of Information Technology, University of Transport Technology, Viet Nam
}

\begin{tabular}{l}
\hline Article Info \\
\hline Article history: \\
Received Oct 27, 2020 \\
Revised Jun 7, 2021 \\
Accepted Jun 15, 2021 \\
\hline
\end{tabular}

Keywords:

LDMOS FET transistor

Power amplifier

Power combiner

Wireless communications

Wilkinson power divider

\begin{abstract}
This article presents the design and fabrication of a high power amplifier based on wilkinson power combiner. A $45 \mathrm{~W}$ basic amplifier module is designed using laterally-diffused metal-oxide semiconductor (LDMOS) field effect transistor (FET) PTFA260451E transistor. Wilkinson power combiner is used to combine two input powers to produce $90 \mathrm{~W}$ of power. The proposed power amplifier is researched, designed and optimized using advanced design system (ADS) software. Experimental results show that the gain is $11.5 \mathrm{~dB}$ greater than at $2.45-3.0 \mathrm{GHz}$ frequency band and achieving maximum power gain of $13.5 \mathrm{~dB}$ at $2.65 \mathrm{GHz}$ centre frequency; output power increased to $49.3 \mathrm{dBm}$; Power added efficiency of $62.1 \%$ and good impedances matching: input reflection coefficient $\left(\mathrm{S}_{11}\right)<-10 \mathrm{~dB}$, output reflection coefficient $\left(S_{22}\right)<-15 \mathrm{~dB}$. The designed amplifier can be used for 4G, 5G mobile communications and S-band satellite communication.
\end{abstract}

This is an open access article under the CC BY-SA license.

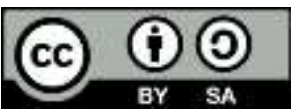

\section{Corresponding Author:}

Tran Van Hoi

Faculty of Electrical and Electronic Engineering

Thuyloi University

175 Tay Son Road, Dong Da Dist, Ha Noi, Viet Nam

Email: hoitv@tlu.edu.vn

\section{INTRODUCTION}

Power amplifier (PA) is an indispensable component in radio communication systems, especially in large distance communication systems such as satellites, mobile communication. PA is the most important block that amplifies the RF signal to power the antenna and provides the highest possible gain with the lowest possible reflectance. There have been many studies on designing and manufacturing power amplifiers performed in different frequency bands [1]-[25] and solving issues such as: increase power and efficiency [3], [6]-[8], [12], [16], increase circuit bandwidth and reduce intermodulation distortion [1], [5], [9]-[11], [13]-[15], [17]-[25].

Recently, different approaches to design high power and wideband PAs have been studyed and proposed around the world. One of the most used research directions is to rely on multi-stage power amplifier circuit [5], [8], [16]. However, this method has low reliablility, because when one of the power amplifiers fails, the system will not function. Other research directions are researched and suggested, in which the designs are based on parallel power amplifier with power divider/combiner [5], [10], [17].

Therefore, this paper focuses on increasing the power of an amplifier using a wilkinson power divider/combiner with a wide frequency band. To do this, two narrowband low-power amplifiers are designed and then combined using the power combiner. Figure 1 shows the block diagram of power amplifier. 
In this case, the article use a 1:2 wilkinson power divider (WPD) and a 2:1 combiner. To guarantee a 90W amplifier output power, A 45W basic amplifier module is designed using LDMOS FET PTFA260451E transistor. To achieve maximum power output, the amplifier input value must reach $33 \mathrm{dBm}$, so the signal before the divider is $36 \mathrm{dBm}$, this is achieved by the pre-amplifiers.

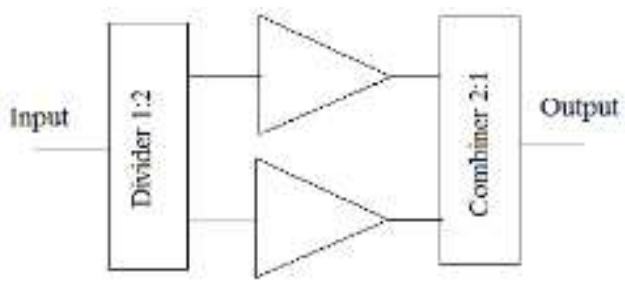

Figure 1. Block diagram of the proposed PA

\section{DESIGN AND SIMULATION}

\subsection{Design of Wilkinson power divider/combiner}

A power dividers is a device used to divide input power into multiple output power according to design requirements and power combiner are used to combine multiple input powers into output power. In practice the designer can use many different types of dividers such as directional couplers, T-junction splitters and Wilkinson splitters. The T-junction power divider is the simplest one, it is a three-port network with one input and two outputs. However, disadvantages of this circuit is the poor isolation between output ports. To solve this problem, a wilkinson power splitter (WPD) will be used in this article. In the winkinson power divider the shunt resistor inserted between the output ports will create a high isolation ability. Single section WPD is shown in Figure 2 [4].

The 2-way Wilkinson power divider uses a quarter wavelength $(\lambda / 4)$ line to coordinate the input $\mathrm{Zo}$ impedance with the $2 * Z$ o impedance connecting the two outputs. Then the impedance of the segment $\lambda / 4$ will be $\mathrm{Z}_{\lambda / 4}=\sqrt{2} * \mathrm{Z}_{0}$. This divider achieves narrow band. In order to achieve wideband divider/combiner, this paper proposes a multi-section impedance matching method with $\lambda / 4$ segments at the $2.65 \mathrm{GHz}$ frequency center. Number of sections is choosen 2 and $\mathrm{Z}_{0}=50 \Omega$, and $\mathrm{Z}_{\mathrm{L}}=100 \Omega$. Table 1 shows the calculation results of the impedance characteristics of the WPD.

The WPD uses a subtrate FR4 $1.5 \mathrm{~mm}$ height with a dielectric substrate of 4.34 and a thickness of $0.035 \mathrm{~mm}$, the length and width of the microstrip line is calculated by lincalc tool in Advance Design System software, the schematic diagram of proposed WPD is shown in Figure 3 and simulation results is shown in Figure 4. From the Figure 4, it can be figured out that the transmission coefficient is good at $-3.3 \mathrm{~dB}$, the forward reflection $\mathrm{S} 11$ is less than $-25 \mathrm{~dB}$ and the attenuation coefficient is less than $-19.0 \mathrm{~dB}$ on the $2 \mathrm{GHz}$ to $3 \mathrm{GHz}$ band.

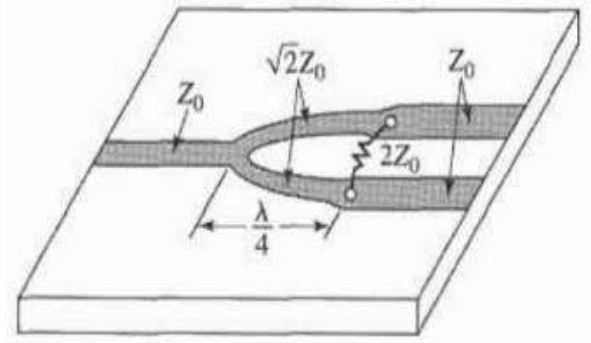

(a)

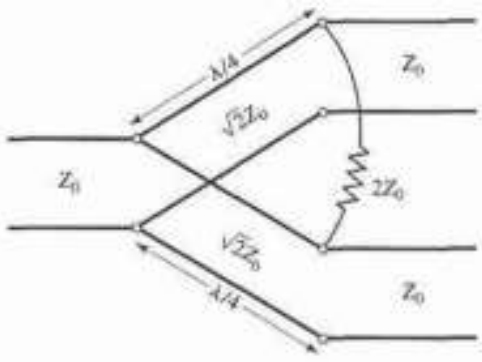

(b)

Figure 2. These figures are; (a) wilkinson power devider in micro-trip form, (b) equivalent transmission line circuit

Table 1. Characteristics impedances of WPD

\begin{tabular}{ccrr}
\hline No of section & Zo & $\mathrm{Z}_{1}$ & $\mathrm{Z}_{2}$ \\
\hline Two & $50 \Omega$ & $84.09 \Omega$ & $59.46 \Omega$
\end{tabular}




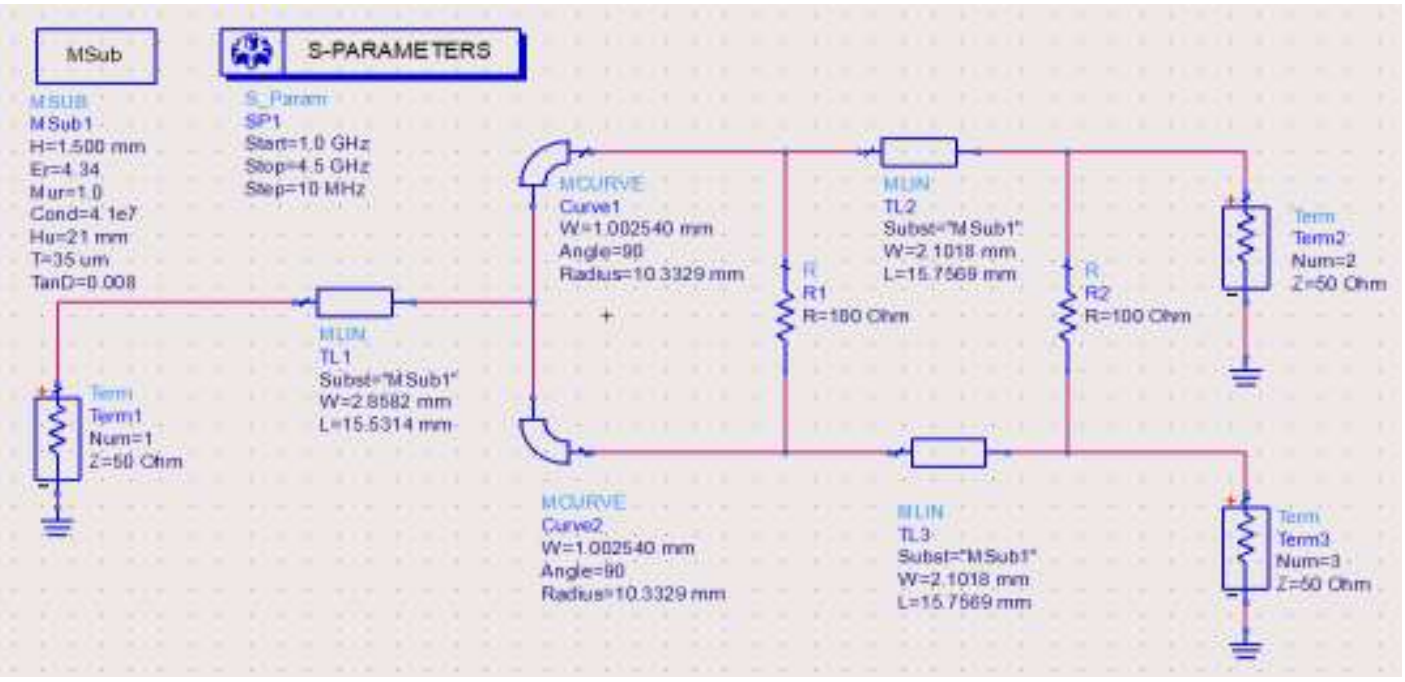

Figure 3. Schematic diagram of multi-section WDP

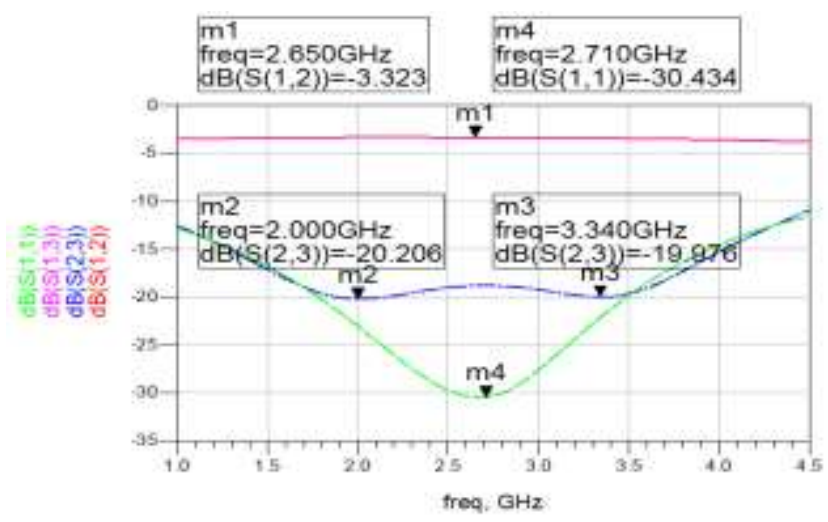

Figure 4. The simulated results of WPD

\subsection{Design of power amplifier}

To design $45 \mathrm{~W}$ power amplifier, the article selects appropriate transistor that is PTFA260451E transistor provided by infineon Technologies. It is a thermally-enhanced high power LDMOS FET transistor with $45 \mathrm{~W}$ output power and operate at $2.65 \mathrm{GHz}$ center frequency. To design a power amplifier is done through the following steps:

Firstly, transistor must be check for stability using the s-parameter of the transistor. The amplifier must be stablilized within the required frequency range. One of the standards used to determine stability of PA is to use parameters $\mathrm{K}$ and $\Delta[4]$ :

$$
\begin{aligned}
& K=\frac{1-\left|S_{11}\right|^{2}-\left|S_{22}\right|^{2}+\left|S_{11} S_{22}-S_{12} S_{21}\right|^{2}}{2\left|S_{12} S_{21}\right|} \\
& \Delta=S_{11} S_{22}-S_{12} S_{21}
\end{aligned}
$$

A PA operates unconditionally stable if $\mathrm{K}>1$ and $|\Delta|<1$.

Secondly, Based on the scattering parameter of the transistor to design a input and output impedance matching of the transistor with the source and load impedance. There are many methods of designing impedance matching such as using lumped elements; microtrip line such as single-stub or double-stub. However, these methods give narrow impedance matching. In order to achieve high power with wideband impedance matching and stability, this design proposes using the multi-section transformers. The PA is designed at $2.65 \mathrm{GHz}$ center frequency. The PA consists of input impedance matching, output matching, and DC biasing is shown in Figure 5. DC power is supplied across quarter-wavelength transmission line so as not to interfere with the AC signals. 


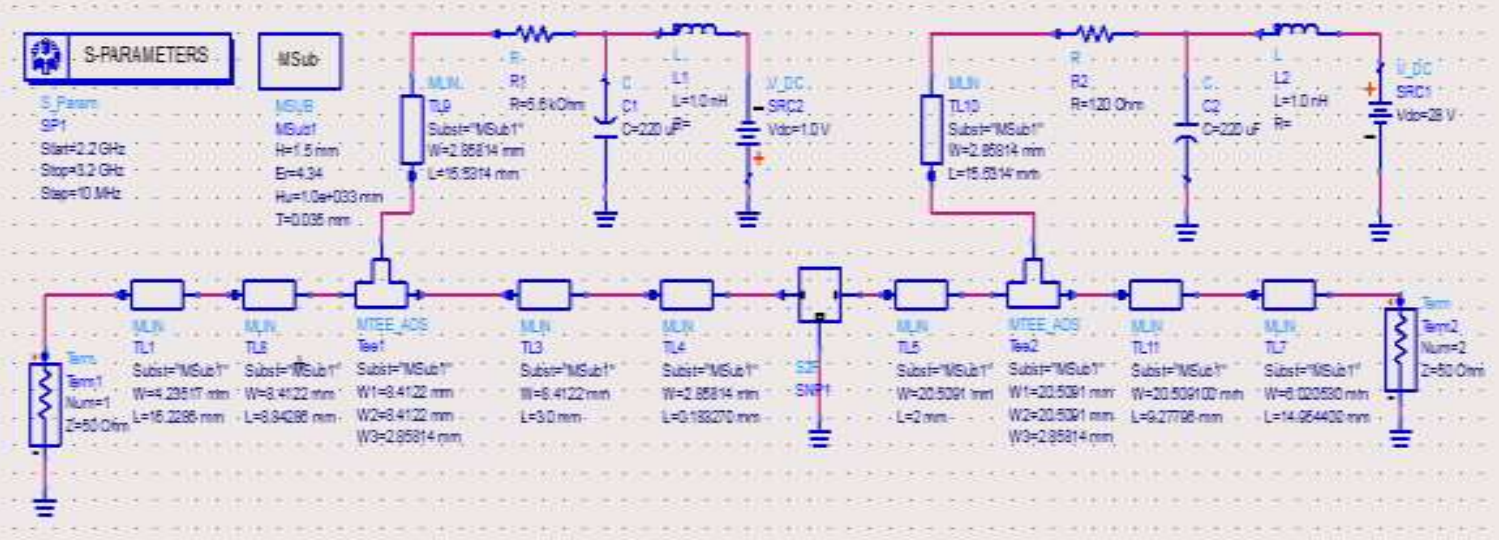

Figure 5. Schematic diagram of PA

The PA also uses the subtrate FR4 with a height of $1.5 \mathrm{~mm}$, dielectric substrate of 4.34 and a thickness of $0.035 \mathrm{~mm}$. To simulate amplifier circuit in small signal mode, the circuit uses scattering parameters with simulated frequency range from 2.2 to $3.2 \mathrm{GHz}$. Figure 6 shows the results of simulation parameters scattering of the proposed PA circuit. From the simulation results in Figure 6, it shows that the power gain of the amplifier circuit is greater than $10 \mathrm{~dB}$ with the isolation coefficient (S12) and the return loss is less than $-10 \mathrm{~dB}$ on bandwidth

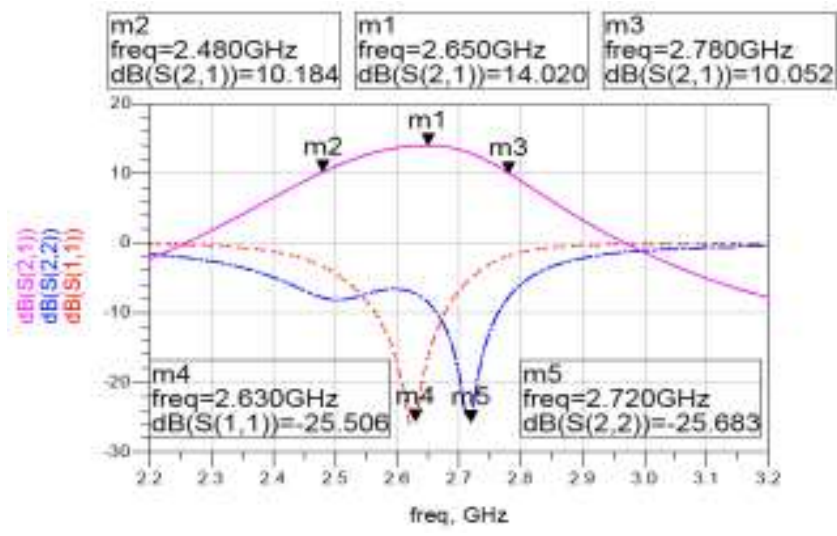

Figure 6. Simulated results of S parameters

For power amplifier circuits, in addition to the characteristic parameters such as output power level $\left(\mathrm{P}_{\text {out }}\right)$, gain $(\mathrm{G})$, there are also extremely important parameters that are drain efficiency $(\mathrm{DE})$ and power added efficiency (PAE). The drain efficiency is determined by the ratio of the output power $\left(\mathrm{P}_{\text {out }}\right)$ to the dissipated power $\left(\mathrm{P}_{\mathrm{DC}}\right)[4]$ :

$$
E=\frac{P_{o u t}}{P_{D C}}
$$

The power added efficiency is defined by the ratio of the difference between the output and the input power to the dissipated power [4]:

$$
P A E=\frac{P_{o u t}-P_{\text {in }}}{P_{D C}}
$$

Perform circuit simulation with supplies power $\mathrm{Vds}=28 \mathrm{~V}$ and $\mathrm{Vgs}=-3.5 \mathrm{~V}$. The power amplifier operates at $2.65 \mathrm{GHz}$ with input power levels from 20 to $45 \mathrm{dbm}$. The Simulation results of power added efficiency are shown in Figure 7. 


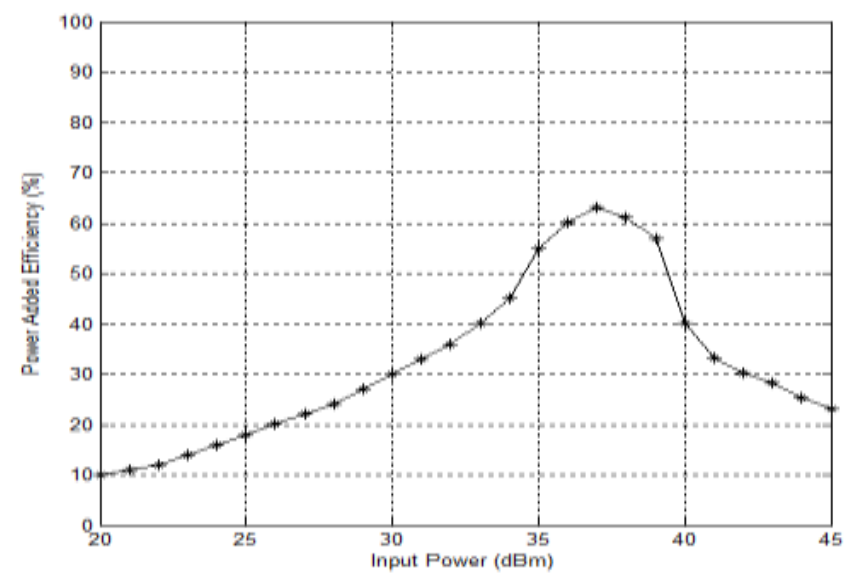

Figure 7. Simulated results of PAE

\section{EXPERIMENTAL RESULTS AND DISCUSSIONS}

Based on the designed WPD circuit, the layout of the circuit is designed and fabricated using the LPKF C40. The WPD's printed circuit board (PCB) is shown in

Figure 8. The WPD's PCB circuit is measured using Vector Network Analyzer Anritsu. The forward transmission of WPD is shown in Error! Reference source not found.. It shows the forward gain of -3.326 $\mathrm{dB}$ in comparison with a simulation's forward gain of $-3.323 \mathrm{~dB}$ in Figure 6.

The PA circuit is designed and fabricated experimentally with supplies Vds and Vgs through the DC and RF filters. The printed circuit board of PA is shown Figure 10. The drain current has measured about $1000 \mathrm{~mA}$. The measured results of S parameter using Vector Network Analyzer is shown in the following figures. The measurement result in the

Figure 10 determines a peak gain of $13.519 \mathrm{~dB}$ at $2.645 \mathrm{GHz}$, working in a wide frequency range from $2.45 \mathrm{GHz}$ to $3 \mathrm{GHz}$ and having a gain greater than $11.5 \mathrm{~dB}$. From Figure 11, it shows that the gain is the same between simulation and the measured results.

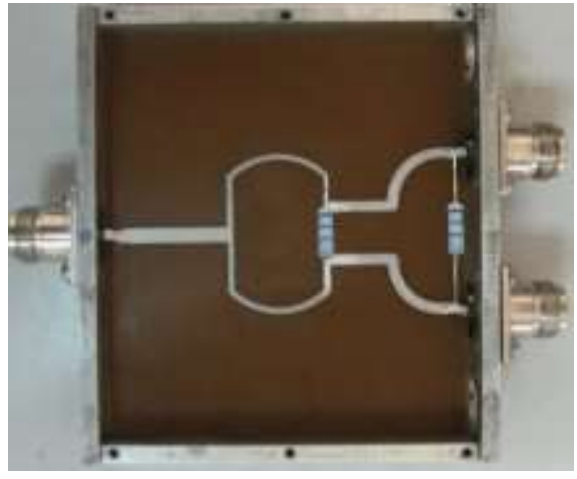

Figure 8. WPD's printed circuit board

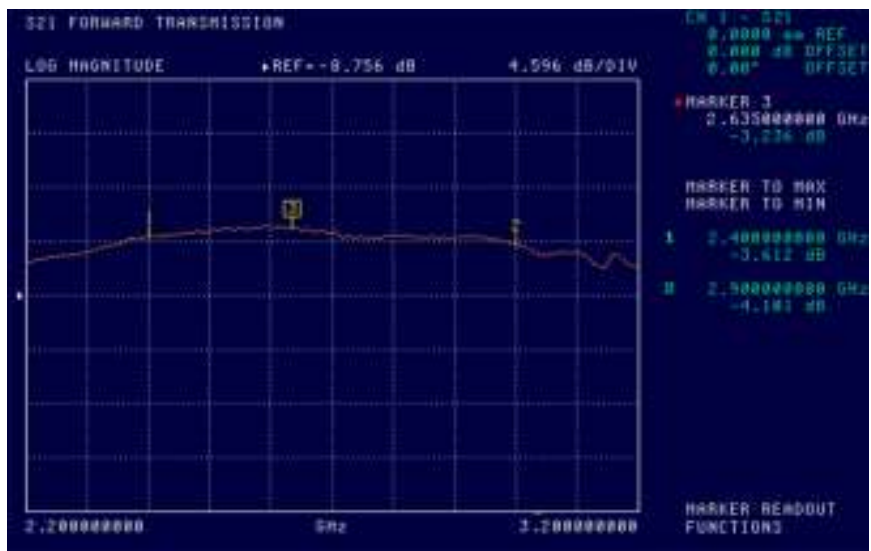

Figure 9. The forward transmission of WPD

From Figure 12, it can be seen the value of the forward reflection $\left(\mathrm{S}_{11}\right)$ achieves $-26.657 \mathrm{~dB}$ at $2.6395 \mathrm{GHz}$ and is less than $-10 \mathrm{~dB}$ in band from $2.5 \mathrm{GHz}$ to $2.8 \mathrm{GHz}$. Looking at the simulation result in Figure 6 and measurement results in Figure 12, it shows a relatively good similarity.

The measurement result of $\mathrm{S}_{22}$ in Figure 13 shows that it reaches $-24.457 \mathrm{~dB}$ at $2.755 \mathrm{GHz}$ and is less than $-15 \mathrm{~dB}$ in the working frequency band. The measured output return loss compared to the simulated value is quite similar. 
The large signals of PA circuit were measured using Spectrum analyzer ESP13 Rohde\&Schwarz and Signal Generator 8648C Agilent. Figure 13 illustrates the measurement's output power of $49.3 \mathrm{dBm}$ at input power of $37 \mathrm{dBm}$.

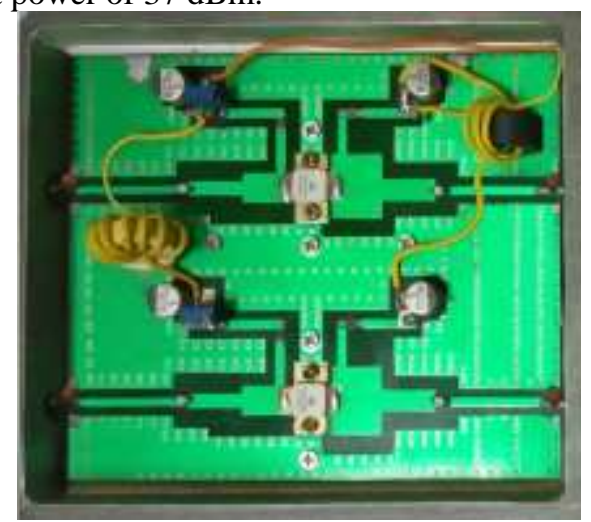

Figure 9. Power amplifier's printed circuit board

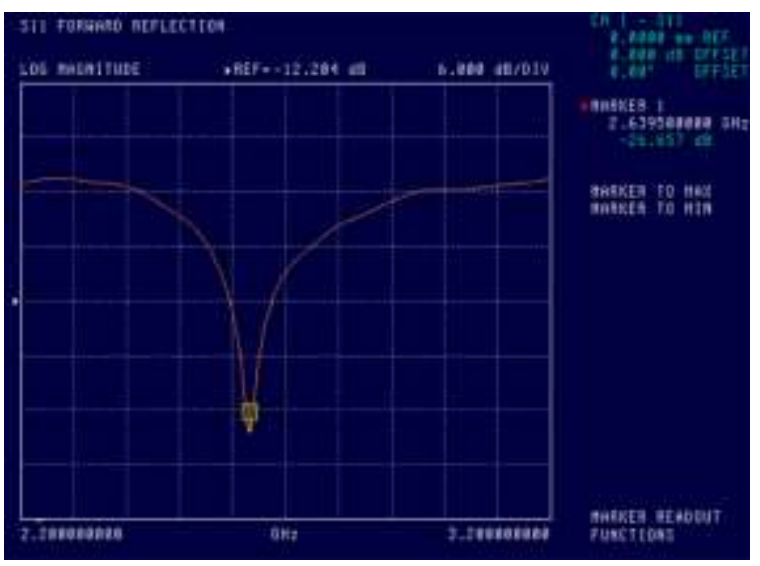

Figure 11. The measurement result of input return loss $\mathrm{S}_{11}$

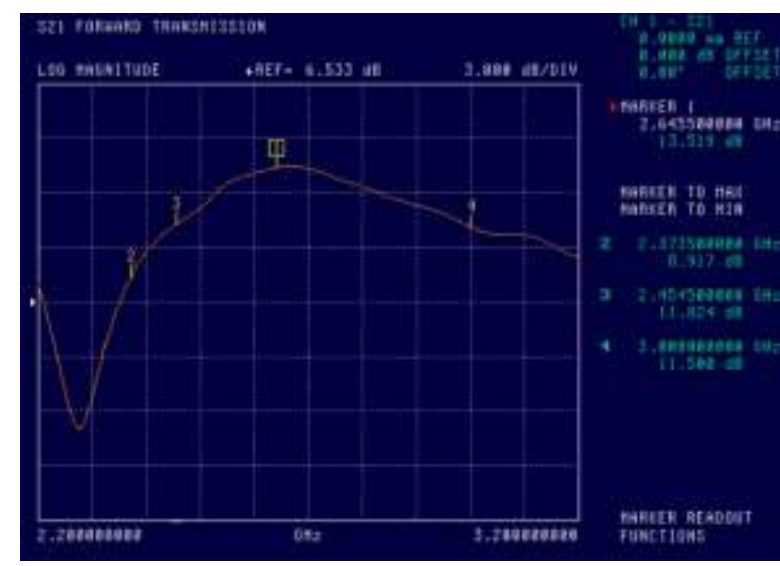

Figure 10. The forward transmission of PA

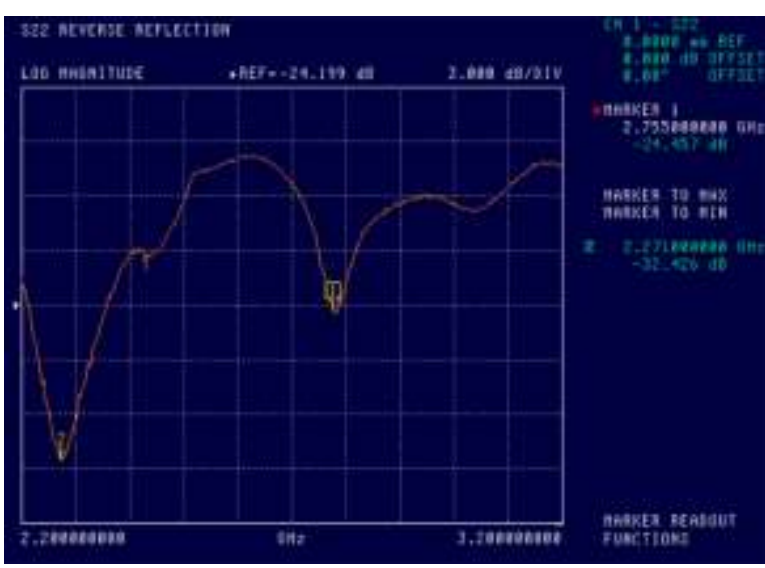

Figure 12. The measurement result of output return loss $\mathrm{S}_{22}$

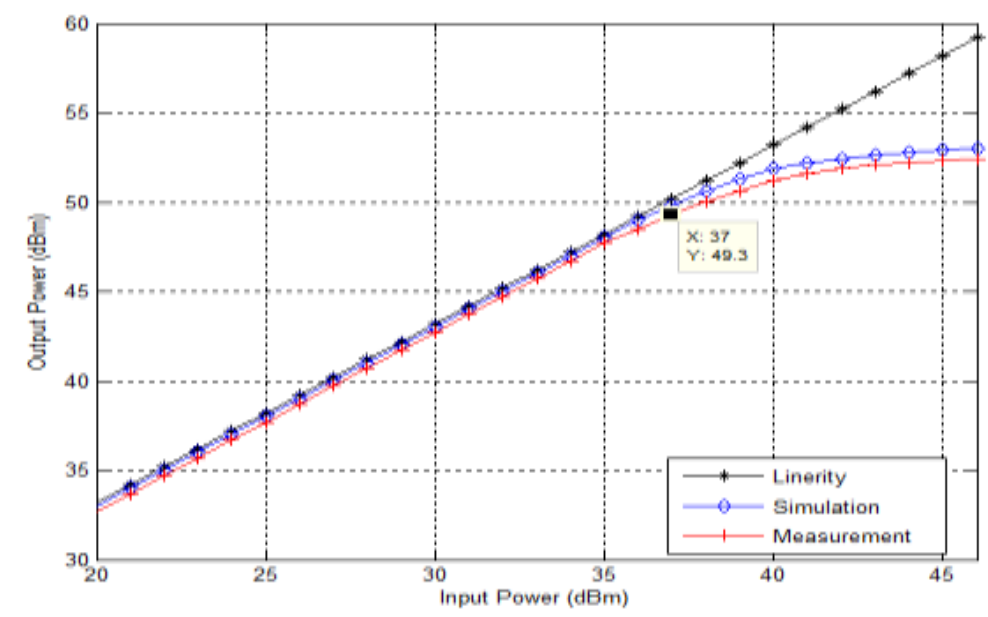

Figure 13. Output power of PA 
Table 2 shows the results of comparing the the power amplifier simulation and measurerment performance in the frequency band $(2.45 \mathrm{GHz}-3.0 \mathrm{GHz})$. The results show a measured gain of $11.5 \mathrm{~dB}$ and a power added efficiency of $61.1 \%$ for an input power of $37 \mathrm{dBm}$ at $2.65 \mathrm{GHz}$. Table 3 shows the results of comparing the parameters of the proposed design with the previously published works. From the table it can be seen that the proposed design has the highest output power and bandwidth.

Table 2. Measured and simulated results with input power of $37 \mathrm{dBm}$

\begin{tabular}{ccc}
\hline & Simulation & Measurement \\
\hline Pout $(\mathrm{dBm})$ & 49.5 & 49.3 \\
Gain $(\mathrm{dB})$ & 14.02 & 11.5 \\
PAE $(\%)$ & 63.2 & 62.1 \\
\hline
\end{tabular}

Table 3. Comparision with state of the art

\begin{tabular}{ccccc}
\hline Reference & Frequency $(\mathrm{GHz})$ & Pout $(\mathrm{dBm})$ & Gain $(\mathrm{dB})$ & PAE $(\%)$ \\
\hline 6 & 2.45 & 50.4 & 9.2 & 62 \\
7 & $2.5-3.8$ & $48.8-49.8$ & $9.3-12.7$ & $54-67$ \\
8 & $1.3-3.4$ & $42.2-43.9$ & $7.2-11.2$ & $45-62.3$ \\
This work & $2.4-3.0$ & $48.5-49.3$ & $11.5-13.5$ & $54-62.1$ \\
\hline
\end{tabular}

\section{CONCLUSION}

In conclusion, the power amplifier for wireless communications at center frequuency of $2.65 \mathrm{GHz}$ has been successfully designed and fabricated. The two $45 \mathrm{~W}$ power amplifiers was designed using LDMOS FET. In addition, combining two power amplifier modules using Wilkinson produces up to 90W of output power. This technology can be applied to combine higher power if it use n-way WPD. The measurement results have been achived the output power of $49.3 \mathrm{dBm}$; PAE of $62.1 \%$; the forward gain of $13.5 \mathrm{~dB}$ is more than $11.5 \mathrm{~dB}$ inband and the input/output return lossed is less than $-10 \mathrm{~dB}$. The designed amplifier can be used for 4G, $5 \mathrm{G}$ mobile communications and S-band satellite communication.

\section{REFERENCES}

[1] Raza, A., and Gengler, J., "Design of a $70 \mathrm{~W}$ Wideband GaN HEMT Power Amplifier with 60\% Efficiency over 100-1000 MHz Bandwidth," in 2018 IEEE Topical Conference on RF/Microwave Power Amplifiers for Radio and Wireless Applications (PAWR), Mar. 2018, pp.72-74, doi: 10.1109/PAWR.2018.8310071.

[2] Rachakh, A., El Abdellaoui, L., Zbitou, J., Errkik, A., Tajmouati, A., and Latrach, M., "A Novel Configuration of a Microstrip Power Amplifier based on GaAs-FET for ISM Applications," International Journal of Electrical and Computer Engineering (IJECE), vol. 8, no. 5, pp. 3882-3889, Oct 2018, doi: 10.11591/ijece.v8i5.pp3882-3889.

[3] A.P. Freundorfer, et al., "A Compact 90W Broadband Doherty Amplifier," In 2016 14th IEEE International New Circuits and Systems Conference (NEWCAS), Jun. 2016, pp. 1-4, doi: 10.1109/NEWCAS.2016.7604742.

[4] David M. Pozar, "Microwave Engineering," John Willey \& Sons, 2005.

[5] Mabrok, M., Zakaria, Z., Sutikno, T., and Alhegazi, A, "Wideband power amplifier based on Wilkinson power divider for S-band satellite communications," Bulletin of Electrical Engineering and Informatics (BEEI), vol. 8, no. 4, pp. 1531-1536, Dec 2019, doi: 10.11591/eei.v8i4.1552.

[6] Nakatani, K., and Ishizaki, T., "A 2.4 GHz-Band 100W GaN-HEMT High-Efficiency Power Amplifier for Microwave Heating," Journal of electromagnetic engineering and science, vol. 15, no. 2, pp. 82-88, Apr. 2015, doi: 10.5515/JKIEES.2015.15.2.82.

[7] Saad, P., Hou, R., Hellberg, R., and Berglund, B., "An 80W Power Amplifier with 50\% Efficiency at 8dB Power Back-off over 2.6-3.8 GHz," In 2019 IEEE MTT-S International Microwave Symposium (IMS), Jun. 2019, pp.13281330, doi: 10.1109/MWSYM.2019.8701113.

[8] Saad, P., Maassen, D., and Boeck, G, "Efficient and Wideband Two-Stage 100 W GaN-HEMT Power Amplifier," In 2014 9th European Microwave Integrated Circuit Conference, Oct. 2014, pp. 337-340, doi: doi:10.1109/eumic.2014.6997861.

[9] Jia, P., You, F., and He, S., "A 1.8-3.4-GHz Bandwidth-Improved Reconfigurable Mode Doherty Power Amplifier Utilizing Switches," IEEE Microwave and Wireless Components Letters, vol. 30, no. 1, pp. 102-105, Jan. 2020, doi: 10.1109/LMWC.2019.2951215.

[10] Bhardwaj, S., and Kitchen, J., "Broadband Parallel Doherty Power Amplifier in GaN for 5G Applications," In 2019 IEEE Topical Conference on RF/Microwave Power Amplifiers for Radio and Wireless Applications (PAWR), May. 2019, pp. 1-3, doi: 10.1109/PAWR.2019.8708727.

[11] Ilamaran, S. G. I., Yusoff, Z., and Sampe, J., "0.5GHz - 1.5GHz Bandwidth 10W GaN HEMT RF Power Amplifier Design," International Journal of Electrical and Computer Engineering (IJECE), vol. 8, no. 3, pp. 1837-1843, Jun. 2018, doi: 10.11591/ijece.v8i3.pp1837-1843. 
[12] Barmala, E., "Design and simulate a doherty power amplifier using GaAs technology for telecommunication applications," Indonesian Journal of Electrical Engineering and Computer Science (IJEECS), vol. 15, no. 2, pp. 845-854, Aug. 2019, doi: 10.11591/ijeecs.v15.i2.pp845-854.

[13] Ribate, M., Mandry, R., Zbitou, J., El Abdellaoui, L., Errkik, A., and Latrach, M., "1.25 GHz - 3.3 GHz broadband solid-state power amplifier for L and S bands applications," International Journal of Electrical and Computer Engineering (IJECE), vol. 9, no. 5, pp. 3633 3641, Oct 2019, doi: 10.11591/ijece.v9i5.pp3633-3641.

[14] Ribate, M., Zbitou, J., Mandy, R., Erkik, A., and Latrach, M., "Broadband GaAs FET Power Amplifier for L and S Bands Applications," International Journal of Intelligent Engineering and Systems, vol. 11, no. 5, pp. 96-105, 2018, doi: 10.22266/ijies2018.1031.09.

[15] Rachakh, A., El Abdellaoui, L., Zbitou, J., Errkik, A., Tajmouati, A., and Latrach, M., "A Novel Configuration of a Microstrip Microwave Wideband Power Amplifier for Wireless Application," TELKOMNIKA (Telecommunication, Computing, Electronics and Control), vol. 16, no. 1, pp. 2014-2031, 2018, doi: 10.12928/telkomnika.v16i1.7369.

[16] MS. Khan, et al., "A Novel Two-Stage Broadband Doherty Power Amplifier for Wireless Applications," IEEE Microwave and Wireless Components Letters, vol. 28, no. 1, pp. 40-42, 2018, doi: 10.1109/LMWC.2017.2775157.

[17] Mabrok, M., Zakaria, Z., and Saifullah, N.,"Design of Wide-band Power Amplifier Based on Power Combiner Technique with Low Intermodulation Distortion," International Journal of Electrical and Computer Engineering (IJECE), vol.8, no. 5, pp. 3504-3511, 2018, doi: 10.11591/ijece.v8i5.pp3504-3511.

[18] Mohamed R., Rachid M., Jamal Z., Larbi A., Ahmed E., Mohamed L., Ahmed L., "A trade-off design of microstrip broadband power amplifier for UHF applications", International Journal of Electrical and Computer Engineering (IJECE), vol. 10, no. 1, pp. 919 927, Feb 2020.

[19] Tan, J., Yuk, K. S., and Branner, G. R., "Design of a high power, wideband power amplifier using AlGaN/GaN HEMT," In 2017 IEEE 18th Wireless and Microwave Technology Conference (WAMICON), 2017, doi: 10.1109/WAMICON.2017.7930252.

[20] Rachakh, A., El Abdellaoui, L., Zbitou, J., Errkik, A., Tajmouati, A., and Latrach, M., "A Novel Design of a Microstrip Microwave Power Amplifier for DCS Application using Collector-Feedback Bias," International Journal of Electrical and Computer Engineering(IJECE), vol. 8, no. 5, pp. 3504-3511, Oct. 2018, doi: 10.11591/ijece.v8i3.pp1647-1653.

[21] Darraji, R., Bhaskar, D., Sharma, T., Helaoui, M., Mousavi, P., and Ghannouchi, F. M., "Generalized Theory and Design Methodology of Wideband Doherty Amplifiers Applied to the Realization of an Octave-Bandwidth Prototype," IEEE Transactions on Microwave Theory and Techniques, vol. 65, no. 8, pp. 3014-3023, Aug. 2017, doi: 10.1109/TMTT.2017.2671438.

[22] Rubio, J. J. M., Camarchia, V., Pirola, M., and Quaglia, R., "Design of an 87\% Fractional Bandwidth Doherty Power Amplifier Supported by a Simplified Bandwidth Estimation Method," IEEE Transactions on Microwave Theory and Techniques, vol. 66, no. 3, pp. 1319-1327, Mar. 2018, doi: 10.1109/TMTT.2017.2767586.

[23] Fang, X. H., Liu, H. Y., Cheng, K. K. M., and Boumaiza, S., "Modified Doherty Amplifier With Extended Bandwidth and Back-Off Power Range Using Optimized Peak Combining Current Ratio," IEEE Transactions on Microwave Theory and Techniques, vol. 66, no. 12, pp. 5347-5357, 2018.

[24] Saad, P., Hou, R., Hellberg, R., and Berglund, B., "A 1.8 - 3.8-GHz Power Amplifier With 40\% Efficiency at 8-dB Power Back-Off," IEEE Transactions on Microwave Theory and Techniques, vol. 66, no. 11, pp. 4870-4882, Nov. 2018, doi: 10.1109/TMTT.2018.2867426.

[25] Jia, P., You, F., and He, S., "A 1.8-3.4-GHz Bandwidth-Improved Reconfigurable Mode Doherty Power Amplifier Utilizing Switches," IEEE Microwave and Uireless Components Letters, vol. 30, no. 1, Jan. 2020, doi: 10.1109/LMWC.2019.2951215

\section{BIOGRAPHIES OF AUTHORS}

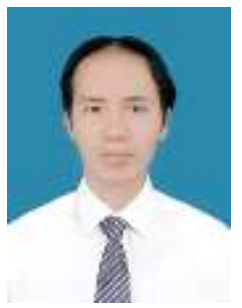

Dr. Tran Van Hoi received an Engineering degree in telecommunication techniques from the University of Transport and communications (UTC) in 2001. He obtained a Master's degree in radio electronics and communications from Le Quy Don Technical University in 2004. From 2001 to 2017, He was a lecturer at College of Radio and Television 1, Radio the Voice of Viet Nam. He received Ph.D degree in Electronics Technology and Communication in University of Engineering and Technology, Viet Nam National University in 2018. Since 2018, He has been working at Thuy Loi University. His research interests relate to RF design, RF chip design, Wirelless Communication. Email: hoitv@tlu.edu.vn.

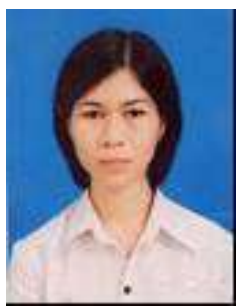

M.S. Ngo Thi Lanh was born in Nam Dinh Province, Viet Nam, in 1977. She received a Bachelor of Electronics and Telecommunications from University of Engineering and Technology, Vietnam National University in 2001. She obtained Master's degree in radio electronics and communications from Le Quy Don Technical University in 2004. From 2001 to 2018, She was a lecturer at College of Radio and Television 1, Radio the Voice of Viet Nam. Since 2019, She has worked at University of Transport Technology. Her research focuses on RF design, Automatic Control, Wirelless Communication. Email: lanhnt@utt.edu.vn 